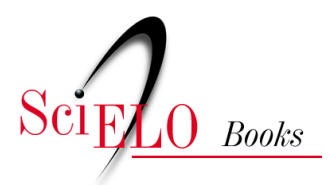

Parte II - Características e manifestações do modelo brasileiro: algumas reflexões

\title{
O Mercosul, o Brasil e a faixa de fronteira do estado do Rio Grande do Sul
}

\author{
Francisco Angst \\ Jorge Adalberto Schommer \\ Letiane Peccin Ristow \\ Micheli dos Santos
}

\section{SciELO Books / SciELO Livros / SciELO Libros}

ANGST, F., SCHOMMER, J.A., RISTOW, L.P., and SANTOS, M. O

Mercosul, o Brasil e a faixa de fronteira do estado do Rio Grande do Sul. In:

ROTTA, E., LOPES, H. C., and ROSSINI, N., eds. O modelo de

desenvolvimento brasileiro das primeiras décadas do século XXI: aportes para o debate [online]. Chapecó: Editora UFFS, 2018, pp. 272-289. ISBN: 978-8564905-82-5. https://doi.org/10.7476/9788564905832.0013.

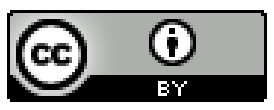

All the contents of this work, except where otherwise noted, is licensed under a Creative Commons Attribution 4.0 International license.

Todo o conteúdo deste trabalho, exceto quando houver ressalva, é publicado sob a licença Creative Commons Atribição 4.0.

Todo el contenido de esta obra, excepto donde se indique lo contrario, está bajo licencia de la licencia Creative Commons Reconocimento 4.0. 


\title{
O MERCOSUL, O BRASIL E A FAIXA DE FRONTEIRA DO ESTADO DO RIO GRANDE DO SUL
}

\author{
Francisco Angst \\ Jorge Adalberto Schommer \\ Letiane Peccin Ristow \\ Micheli dos Santos
}

\section{INTRODUÇÃO}

O Mercado Comum do Sul (Mercosul) é um bloco econômico representativo na América Latina. Medeiros, Meunier e Cockles (2015) afirmam que, desde sua fundação, em 1991, o Bloco tem sido qualificado por seus mecanismos intergovernamentais e pelo processo de tomada de decisão fundado no consenso. Conforme Ventura (2005), desde sua implementação, pela assinatura do Tratado de Assunção, o Mercosul tem alternado sua história com momentos de progresso e estagnação.

O conjunto de processos de transformações institucionais, estratégicos e normativos induzidos pelo Mercosul configura-se em políticas regionais que visam ao desenvolvimento integrado do Cone Sul e de toda América Latina (MODOLO, 2015). Conforme Botto (2011), a partir de cinco políticas regionais - educação, ciência e tecnologia, produção e consumo sustentável, integração produtiva e assimetrias -, o Mercosul concebe um processo de harmonização de políticas desde o nacional ao regional, mais do que um processo de transferência do global ao regional. Sendo assim, 
seus países mais desenvolvidos - Brasil e Argentina - seriam os que impõem suas políticas aos menores.

Assim, faz-se necessário conhecer a história do Mercosul ao longo dos seus 25 anos de constituição, recentemente completados. Para isso, parte-se do Tratado de Assunção, marco histórico de constituição do Mercado Comum do Sul, percorrendo-se cronologicamente seu processo evolutivo em determinados aspectos, tais como a constituição de sua estrutura e suas instituições, dentre elas o Parlamento do Mercosul, processo ocorrido ao longo de fases, segundo Hoffmann (2008). Cabe uma breve análise da relevância do Brasil perante a consolidação do Mercosul, no intuito de identificar seu papel enquanto membro desse conglomerado, averiguando quais as possibilidades e potencialidades dos países-membros para a estruturação de uma cadeia de produção regional que possa, além de integrar o Bloco, também proporcionar alavancagem ao desenvolvimento de seus países.

Nesse contexto, o que já foi percorrido pelos países-membros, o que foi realizado pelo Brasil, bem como sua responsabilidade perante o conjunto e à inserção sul rio-grandense, são conteúdos muito ricos para a elucidação de vitórias e fracassos ao longo desses 25 anos de integração. Por fim, esta revisão objetiva reconhecer o quanto já se avançou e o que é necessário progredir, pois aprender com o passado, avaliar o presente e trilhar caminhos para o futuro é fundamental para estabelecer novos rumos.

\section{MERCOSUL: HISTÓRICO E CRONOLOGIA}

O Mercosul surgiu como ferramenta para expansão dos mercados nacionais de seus países-membros, frente à globalização e ao processo de formação de blocos econômicos. Composto inicialmente por Brasil, Argentina, Uruguai e Paraguai, o Mercosul firmou seus propósitos, princípios e instrumentos no Tratado de Assunção, assinado em 26 de março de 1991, em Assunção, no Paraguai. No Brasil, este tratado foi legitimado 
pelo Decreto Legislativo no 197 , de 25 de setembro de 1991, e promulgado pelo Decreto no 350, de 21 de novembro de 1991.

Anteriormente à assinatura do Tratado de Assunção, Argentina e Brasil voltavam suas perspectivas ao desenvolvimento regional, baseado em um modelo estruturalista intervencionista (BRICEÑO-RUIZ, 2011), pré-consenso liberal. Com a consolidação do processo de globalização, na década de 1990, é que a integração regional começou a ser vislumbrada como um plano de desenvolvimento pelo prisma da inserção internacional. Isso ocorreu devido ao fato de, na década de 1980, o Brasil e a Argentina começarem a enfrentar os efeitos da exaustão do modelo de desenvolvimento traçado em estratégias protecionistas, agravando-se as desigualdades sociais e o atraso econômico, aumentando as pressões causadas pelo endividamento externo (SARAIVA; BRICEÑO-RUIZ, 2009).

A partir de então, o Bloco convencionou atributos do "regionalismo aberto $^{1 "}$, com ausência de uma agenda de "integração profunda" e de mecanismos para avançar na integração social e produtiva (BRICEÑO-RUIZ, 2013, p. 259). Ainda assim, nos primeiros anos o Mercosul estava voltado quase que unicamente para questões comerciais (BRICEÑO-RUIZ, 2011), o que possibilitou a Hoffmann et al., (2008, p. 101) afirmar que "embora vise à integração dos mercados, o bloco não ultrapassou a condição de uma união aduaneira imperfeita", apesar de ter progredido em outros panoramas que não o econômico-comercial.

Ao longo dos seus 25 anos, o Mercosul passou por fases distintas. Hoffmann et al. (2008), após análise de indicadores econômicos, políticos e sociais de integração, identificaram três fases:

A primeira pode ser chamada de fase de formação e compreende o período entre 1991 e 1997, durante o qual é constituída a estrutura

1 O termo "regionalismo aberto" foi definido pela CEPAL (1994), como: “[...] um processo de crescente interdependência no nível regional, promovida por acordos preferenciais de integração e por outras políticas, num contexto de liberalização e desregulação capaz de fortalecer a competitividade dos países da região e, na medida do possível, constituir a formação de blocos para uma economia internacional mais aberta e transparente". 
institucional do bloco. A ênfase é dada ao aspecto comercial do processo de integração, com a criação de órgãos destinados a tratar do tema. A segunda fase, que vai de 1998 a 2002, foi uma fase de crise, como um reflexo da crise econômica pela qual os países passavam. Uma terceira fase se delineia a partir de 2003, quando há uma retomada do processo de integração, coincidindo com uma renovação na política doméstica dos países, com governos mais alinhados com a esquerda chegando ao poder: no Brasil, Luis Inácio Lula da Silva, na Argentina, Néstor Kirchner, e no Uruguai, Tabaré Vázquez (HOFFMANN et al., 2008, p. 103).

Todas as fases foram marcadas por restrições tanto do contexto interno como externo. A primeira fase, em 1991, combinou com o Plano Cavallo $^{2}$ na Argentina, que deu origem à lei de conversibilidade entre o peso e o dólar e engloba o período de estabilização da moeda brasileira, com o Plano Real, iniciado em 1994 (CURZEL, 2013).

Nesta fase inicial, segundo Hoffmann (2008), foram criados órgãos de base, com representação do executivo de cada país, tais como Conselho do Mercado Comum (CMC), Grupo Mercado Comum (GMC), Comissão de Comércio do Mercosul (CCM), Comissão Parlamentar Conjunta (CPC), Fórum Consultivo Econômico-Social (FCES) e a Secretaria Administrativa do Mercosul, além da criação de um sistema de solução de controvérsias do Mercosul. Tais órgãos foram fundamentais para a estruturação consultiva, deliberativa e normativa do bloco. Neste período foi notável, também, o fortalecimento da relação comercial intrabloco, passando de 13\% em 1991 para 23\% em 1997 do comércio entre estes países.

De acordo com Mallmamm e Marques (2013), na segunda fase (19982002) chegam ao poder forças políticas progressistas. Esse período culminou com a exaustão do modelo de abertura econômica adotado no início da década de 1990 e com violentos problemas sociais acompanhados de desdobramentos políticos e eleitorais. No cenário internacional, surgiram

2 O Plano Cavallo foi um pacote econômico de estabilização monetária na Argentina, coordenado pelo ministro da Economia Domingo Cavallo. O principal objetivo do plano era o combate à inflação. 
preocupações estratégicas decorrentes dos atentados de 11 de setembro de 2001 nos Estados Unidos, ocasionando uma conjuntura menos confiável e propícia a projetos liberais.

O período de 1998 a 2002 aponta para uma estagnação na relação do Bloco, grande parte devido à crise enfrentada por alguns países-membros; cabe destacar, entretanto, $\mathrm{o}$ avanço nas diretivas criadas neste período, sendo 51 normas entre os anos mencionados. Foi criado, nesta fase, o Foro de Consulta e Concertação Política, integrando funcionários da chancelaria dos estados-membros, com o objetivo de avançar em temas relativos à política comum. No âmbito econômico, esse período ficou caracterizado pela crise e redução de suas relações comerciais. Hoffmann (2008) destaca, nesse sentido, a desvalorização da moeda brasileira promovida em 1999, o que repercutiu negativamente na Argentina, que, como medida protetiva, ampliou algumas de suas tarifas acima da tarifa externa comum do Mercosul.

$\mathrm{Na}$ terceira fase houve um processo de revitalização. Foram estabelecidos avanços não apenas na relação comercial, mas os países-membros passaram a incluir em suas agendas discussões e instruções relativas a direitos humanos, democracia e questões sociais, e, em 2004, notadamente, foram criados, no âmbito da CMC, Fóruns Consultivos de Municípios, Estados Federados, Províncias e Departamentos. Percebe-se nisto uma expansão e preocupação em promover a participação das demais esferas federativas. Destaca-se ainda a criação do Fórum de Convergência Estrutural do Mercosul (Focem). Para Hoffmann (2008), “O Focem tem caráter redistributivo e representa a disposição de Brasil e Argentina em arcar com certos custos da integração, uma vez que são os maiores contribuintes do fundo, mas recebem a menor parte dos recursos."

Constitui-se, neste período, o Parlamento do Mercosul, que teve sua primeira legislatura entre 2007 e 2010; todavia, ele possui função consultiva junto ao CPC e nenhuma competência legislativa. Também neste período estabelece-se o Instituto Mercosul de Formação (IMEF), com o objetivo 
acadêmico para capacitação e especialização de funcionários públicos na temática da integração regional.

A terceira fase coincide com a recuperação da economia e do comércio mundiais, vindo a encerrar-se em 2008, com a crise internacional, que impôs ao Bloco incluir em sua agenda temas políticos e sociais. "Neste sentido, o Mercosul não é só comércio, mas um processo multifacetário no qual os elementos comerciais estão misturados com objetivos sociais, produtivos e, até mesmo, políticos”. (BRICEÑO-RUIZ, 2013, p. 275). A Figura 1 apresenta as principais etapas históricas na criação do Mercosul.

Figura 1: Etapas históricas do Mercosul

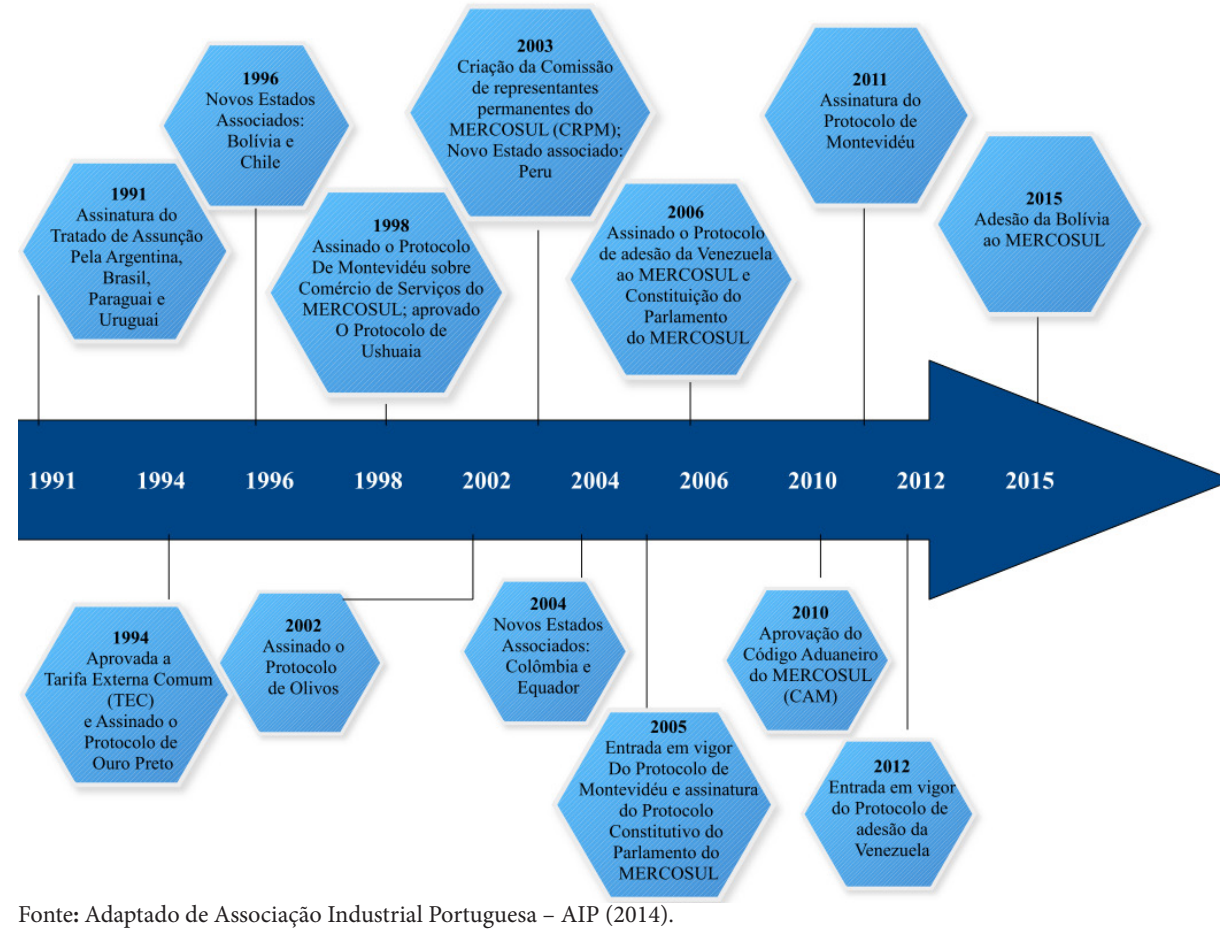

Conforme se observa na Figura 1, esforços têm sido feitos para consolidar a integração política, econômica e social, tonificar os vínculos entre os cidadãos do Bloco e cooperar para melhorar a qualidade de vida, 
embora, mesmo após 25 anos de existência, o Bloco não tenha conseguido realizar totalmente seu processo de integração, sendo identificado como uma união aduaneira imperfeita.

Para além da percepção de que o Mercosul ainda não atingiu completamente seu objetivo de integração, há que considerar-se, a partir do processo evolutivo mostrado na Figura 1, que se avançou em normativas, destacando-se a criação do Parlamento do Mercosul, como também a constante aceitação de inserção de novos parceiros comerciais, como os Estados Associados do Chile, Equador e Colômbia, para além da Bolívia que, recentemente, aderiu ao Bloco.

Após um apanhado geral sobre o Mercosul, analisa-se, na sequência, a importância do Brasil, enquanto maior economia do Bloco, na condução do processo de integração regional.

\section{ANÁLISE DA INSERÇÃO BRASILEIRA E SUA RESPONSABILIDADE NO BLOCO}

No contexto do Mercosul, o Brasil figura como principal país. Segundo a Associação Industrial Portuguesa (AIP, 2014), os países-membros possuem grandes assimetrias que envolvem tamanho territorial, questões culturais, geográficas e econômicas. A Figura 2 representa a participação econômica de cada país-membro, apontando a supremacia do Brasil comparado aos demais, o que fundamenta sua importância no Mercosul.

Segundo Moreira e Miranda (2012), na economia mundial o Mercosul situa-se como terceiro maior bloco econômico do mundo, atrás do NAFTA e da UE, com um PIB aproximado de US\$ 3,0 trilhões. Desse total, o Brasil participa com 71\% (Figura 2). Isso pode resultar em problemas, uma vez que as economias mais fortes tendem a ter mais vantagens comerciais e econômicas, impondo-se naturalmente no mercado de outros países (AIP, 2014; MOREIRA; MIRANDA, 2012). 
Figura 2: Produto Interno Bruto dos países-membros do Mercosul

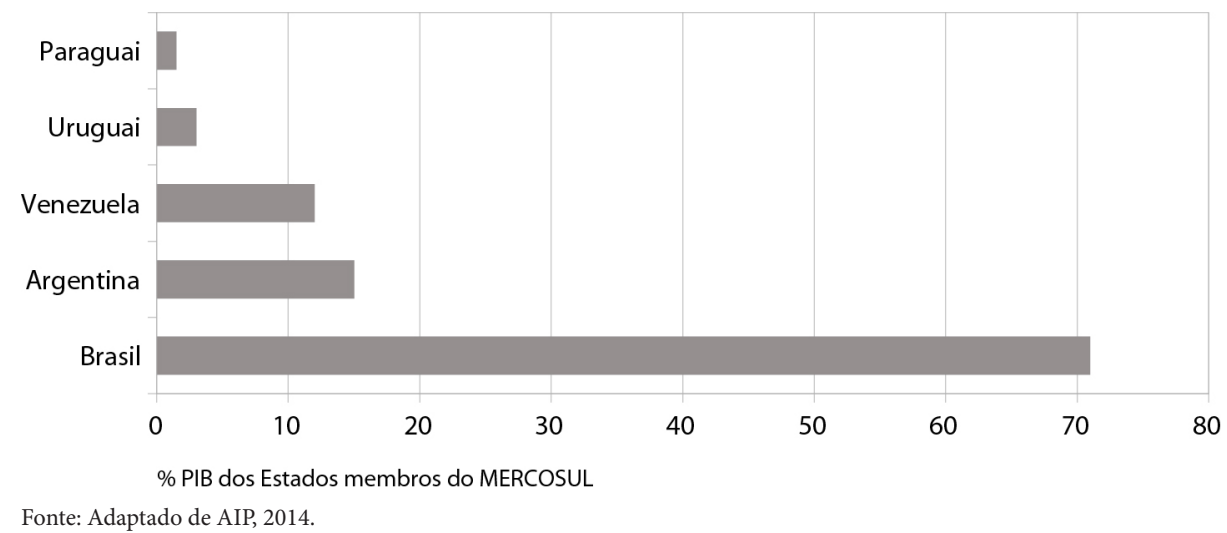

A contribuição econômica brasileira é 15 vezes maior que a do $\mathrm{Pa}$ raguai e Uruguai juntas, e o valor agregado das mercadorias exportadas pelo Brasil e Argentina é maior. Essa discrepância cria um superavit em favor dos países mais eminentes do grupo (MOREIRA; MIRANDA, 2012). Conforme o Tratado de Assunção (1991), no seu artigo $1^{\circ}$, que estabelece a livre circulação de bens, serviços e fatores produtivos entre os países, esse predomínio econômico-financeiro do Brasil pode eclodir em favorecimentos, o que vai contra as condições do tratado.

Há que considerar-se que uma adequada política do Estado Brasileiro quanto à integração do Bloco e à potencialização das vantagens competitivas regionais pode promover a estruturação de cadeias produtivas e até mesmo a inserção do Bloco em cadeias já existentes, aos moldes do que já começava a ocorrer na Europa Ocidental na década de 50 e 60, como aponta Miranda (2014), através da complementaridade dos parques produtivos nacionais. Essa postura adotada pelo Brasil, que possui maior influência comercial e econômica no Bloco, poderia inserir o Bloco nas cadeias globais de produção de tecnologia e distribuição de bens e serviço, atendendo um comércio global e principalmente chinês já ávido pelas matérias-primas dos países do Mercosul, notadamente no Brasil. 
O Brasil, de modo tímido, assimila não somente esse papel, mas a articulação e união do Bloco. Segundo Miranda (2014), tanto o Brasil quanto o Mercosul tem intensificado suas negociações com a União Europeia e mesmo com o grupo do BRICS (Brasil, Rússia, Índia, China e África do Sul), que se torna potencial para o desenvolvimento através de joint ventures nas áreas de energias renováveis, fármacos, aeronáutica e informática. Nesse sentido, o Brasil tem interesse na promoção da maior integração física, produtiva e comercial da América do Sul como um todo.

De acordo com Moreira e Miranda (2012), a característica integradora faz do Brasil, no Mercosul, uma grande influência política e econômica, composicionamento a favor do multilateralismo para enfrentar a posição norte-americana e a tentativa de implementação da área de livre comércio das Américas.

Miranda (2014) afirma que o Brasil deve concentrar seus esforços na definição de uma agenda relevante com os agentes econômicos dos demais países-membros do Bloco, para a integração produtiva e comercial, tanto regional quanto internacional. Isso pode permitir uma maior integração regional com o fortalecimento dessas relações e uma melhor inserção no comércio global. Dessa forma o Brasil deve assumir seu papel e buscar agilizar o processo de liberalização comercial do Mercosul e deste sub-bloco com os demais países sul-americanos.

Para a AIP (2014), a complementaridade entre os estados-membros do Mercosul é reduzida e carece de uma intensificação em suas relações comerciais, para a qual se torna necessário incremento na especialização dos países integrantes, proporcionando, assim, por consequência, o desenvolvimento de cadeias de valor regionais. Nesse aspecto, segundo o relatório da AIP (2014), o Brasil, pelo nível de industrialização mais elevado e pela especialização, assume papel mais relevante na comunidade econômica regional, porém isso por si só não basta. Tudo isso depende 
muito da intensificação das políticas e dos esforços de integração dos diferentes países que compõem o bloco.

Nas referências apresentadas, os autores convergem na percepção do papel proeminente do Brasil para a continuidade do processo de integração e fortalecimento do Bloco diante das relações comerciais no âmbito global. A riqueza de matéria-prima existente no Brasil e nos países do Mercosul já é visada pela China, para o atendimento de sua demanda interna, que se desenvolve em larga escala e começa a expandir-se para o resto do globo. A dimensão continental do território brasileiro e a rica diversidade cultural, de riquezas naturais, produtiva e estrutural, faz com que seja necessário identificar as especificidades e potencialidades das regiões que compõem o Estado Brasileiro, pois as características regionais são relevantes e devem ser levadas em consideração. Saber como esses estados-membros da República Federativa do Brasil estão inseridos no processo de integração através das ações locais torna-se um aspecto a ser amplamente explorado, para que o Mercosul alcance seus objetivos na continuidade do processo de integração.

\section{FAIXA DE FRONTEIRA NO RIO GRANDE DO SUL}

Devido às dimensões do território brasileiro e sua vasta área de fronteira é necessário estudar os aspectos regionais e sua importância para a integração do Mercado Comum do Sul.

A integração sul-americana inclui intrincado debate entre normas jurídicas e políticas públicas. O instrumento de integração de fronteiras demanda visão estratégica dos instrumentos legais disponíveis e empreende comprometimento entre países para arquitetar o desenvolvimento, a partir de critérios soberanos cooperativos. Por conseguinte, "a base normativa deve acompanhar a evolução dos acordos internacionais de forma 
que a internalização dos compromissos firmados entre os Chefes de Estado consolide as bases do Mercosul" (FURTADO, 2011, p. 9).

Discutir assuntos na esfera do Mercosul requer o simultâneo diálogo sobre assuntos fronteiriços e regionais, pois é o empenho comum de poderes tanto locais como internacionais em superar as adversidades da aproximação que fará do Mercosul um sucesso ou uma frustração.

Na Constituição Federal Brasileira, o segundo parágrafo do art. 20 esclarece que a faixa de fronteira corresponde a uma área de até cento e cinquenta quilômetros de largura, ao longo das fronteiras terrestres. $\mathrm{O}$ Brasil ocupa um território de 8,5 milhões de $\mathrm{km}^{2}$, sendo o quinto país do mundo em extensão territorial.

Em relação aos demais países que integram o Mercosul, o Brasil possui maior espaço de diálogo com outras nações, pois faz fronteira com dez países (FURTADO, 2011). Já o Rio Grande do Sul faz fronteira com Argentina e Uruguai.

No estado do Rio Grande do Sul, as faixas de fronteira correspondem a áreas que fazem divisa com a Argentina e o Uruguai, as quais, juntamente aos estados de Santa Catarina e Paraná, formam o Arco Sul do Brasil, conforme demonstrado na Figura 3. 
Figura 3: Faixa de Fronteira no Brasil e no Rio Grande do Sul

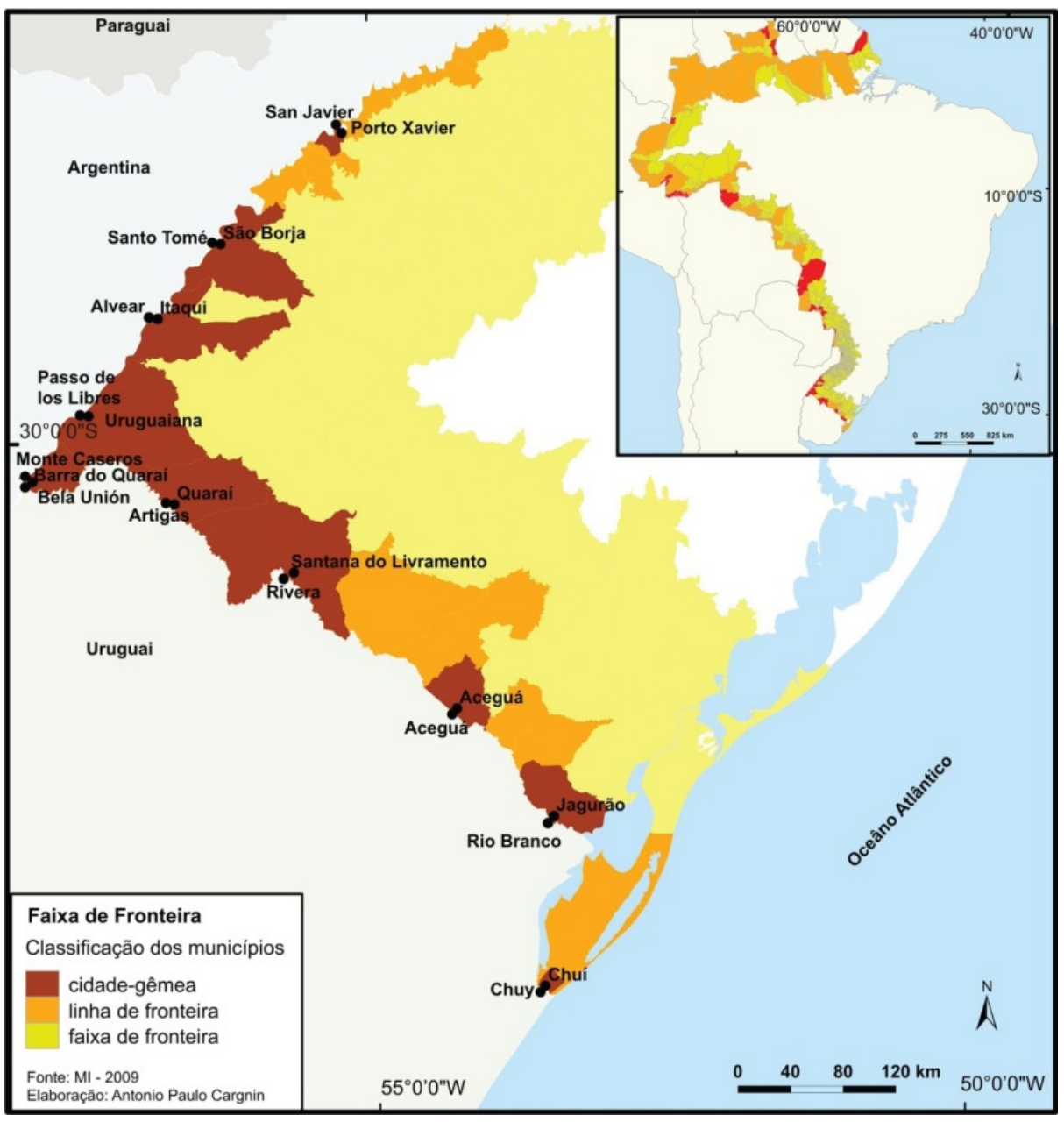

Fonte: Ministério da Integração Nacional, 2009.

Na Figura 3 observa-se a classificação dos municípios da faixa de fronteira, a qual é entendida da seguinte forma: municípios que fazem divisa com os países vizinhos são classificados como de "linha de fronteira", e os que se unem diretamente com um ou mais vizinhos são chamados de “cidades-gêmeas". O Estado do Rio Grande do Sul, devido a sua ocupação 
e características, apresenta dez cidades-gêmeas, o maior número entre todos os estados brasileiros.

O Ministério da Integração Nacional estabeleceu o conceito de cidades-gêmeas nacionais, os critérios adotados para essa definição e a lista de todas as cidades brasileiras por estado que se enquadram nessa condição. Essas informações constam da Portaria no $125 / 2014$, cujo art. $1^{\circ}$ define:

Art. $1^{\circ}$ Serão considerados cidades-gêmeas os municípios cortados pela linha de fronteira, seja essa seca ou fluvial, articulada ou não por obra de infraestrutura, que apresentem grande potencial de integração econômica e cultural, podendo ou não apresentar uma conurbação ou semiconurbação com uma localidade do país vizinho, assim como manifestações "condensadas" dos problemas característicos da fronteira, que aí adquirem maior densidade, com efeitos diretos sobre o desenvolvimento regional e a cidadania (BRASIL, 2014).

Segundo Cagnin (2014), no Rio Grande do Sul as intervenções do Plano Nacional de Desenvolvimento Regional (PNDR) se restringiram aos instrumentos denominados de planos e programas nas escalas macrorregional e regional na região de Fronteira, pelo Programa de Desenvolvimento da Faixa de Fronteira (PDFF), que tem viabilizado projetos nas chamadas cidades-gêmeas, destinados à melhoria de infraestrutura, saneamento, urbanização, saúde e educação. As principais repercussões do Programa foram a criação do Fórum da Mesorregião da Metade Sul e da Mesorregião Grande Fronteira do Mercosul, este último envolvendo o oeste de Santa Carina e do Paraná, surgindo disso a criação da Universidade Federal do Pampa (UNIPAMPA) e da Universidade Federal da Fronteira Sul (UFFS), cujo debate foi alimentado pelos fóruns regionais.

Ainda, segundo o mesmo autor, o Ministério de Integração Nacional (MI) tem promovido o debate sobre o desenvolvimento nas regiões através da realização sistemática de seminários, reuniões técnicas e formações e, também, promovendo o envolvimento dos demais órgãos e instituições 
governamentais, estabelecendo parcerias entre os Governos Estaduais, Municipais, Fóruns das Mesorregiões citadas e os Conselhos Regionais de Desenvolvimento.

Nota-se que há uma demanda crescente pela definição de políticas públicas específicas para estes municípios fronteiriços, considerando que geralmente a divisão entre eles se dá por uma rua, tornando-os de extrema importância para a integração sul-americana.

Nesse sentido, o governo do estado do Rio Grande do Sul, através do Núcleo Regional de Integração da Faixa de Fronteira, elaborou o Plano de Desenvolvimento e Integração da Faixa de Fronteira do Estado do Rio Grande do Sul (PDIF/RS), compreendendo um vasto processo de planejamento participativo e muitas instituições e atores, tanto governamentais quanto da sociedade civil, com o objetivo de articular o desenvolvimento econômico e social dos territórios de fronteira, diversificando a economia, fortalecendo as cadeias produtivas existentes e promovendo crescimento econômico com sustentabilidade ambiental e equidade social (RS, 2012).

Para além das preocupações com os aspectos econômicos e sociais, $\mathrm{o}$ PDIF/RS (2012) aponta para as questões referentes à infraestrutura como fundamental para o desenvolvimento, considerando que investimentos em estradas, ferrovias, pontes, aeroportos, redes de energia elétrica e conectividade são condições indispensáveis para o crescimento econômico, para a qualidade de vida e para sua maior integração, devendo ser priorizados, tanto pelo governo federal como pelos demais organismos multilaterais de investimentos voltados para a integração latino-americana.

\section{CONSIDERAÇÕES FINAIS}

Após fazer esta análise do contexto do Mercosul, sua constituição e histórico evolutivo, foi possível averiguar alguns aspectos do papel do 
Brasil frente ao Bloco e, fundamentado nisso, partir para uma análise local, pela abordagem da importância do Rio Grande do Sul no processo de integração.

Se por um lado o Mercado Comum do Sul, em seus 25 anos de história, não atingiu sua integração plenamente, conforme alguns autores, por outro lado não é negado pela revisão de literatura que, em alguns momentos, houve progresso, principalmente no período inicial, entre $1991 \mathrm{e}$ 1997, com a ênfase no aspecto comercial.

O Brasil figura nesse processo cercado de uma responsabilidade mais acentuada, tendo em vista tratar-se da economia mais relevante do Bloco, e por possuir um parque industrial mais consistente, são esses os aspectos apontados pelos autores. Conforme visto, o Brasil tem relevância no processo de fortalecimento da integração na medida em que tem mais condições de dar suporte aos menores países membros. Para além disso, tem potencial para impor-se comercialmente em conjunto com o bloco perante o mercado internacional.

As diversidades regionais de um país de dimensões continentais como o Brasil não podem ser esquecidas ou deixadas à margem do processo e, por esse motivo, foram abordados aspectos da integração do estado do Rio Grande do Sul e sua faixa de fronteira com a Argentina e o Uruguai. Foi possível apurar que tanto a União quanto os estados empreendem esforços para promover e consolidar a integração, tanto em aspectos estruturais quanto comerciais, políticos e sociais.

Apesar de sua tenra caminhada, em relação aos demais blocos econômicos existentes, percebe-se que a agenda do Mercosul têm conseguido dar passos importantes para a consolidação do bloco, tantointra como extra-Bloco. Esse processo torna-se fundamental para o fortalecimento e a continuidade da integração. 


\section{REFERÊNCIAS}

ALMEIDA, P. R. O desenvolvimento do MERCOSUL: progressos e limitações. Revista Espaço da Sophia, Brasília, ano 5, nº 43, p. 63-79, 2011.

Associação Industrial Portuguesa (AIP). BRASIL Integração regional no MERCOSUL e relacionamento com os países da CPLP. Disponível em: $<$ http://www.aip.pt/irj/go/km/docs/site-manager/www_aip_pt/documentos/ internacionalizacao/internacionalizacao/informacao/Lusofonia $\% 20$ Econ\%C3\%B3mica/4\%20-\%20BRASIL,\%20MERCOSUL\%20-\%20CPLP. pdf>. Acesso em: 27 jun. 2016.

BOTTO, M. Qué nos enseñan los 20 años del Mercosur? Nueva Sociedad, 232, p. 17-25, 2011.

. El Mercosur, ¿para qué sirve? Claves para el debate sobre los alcances de la Integración. Buenos Aires: FLACSO/CTA, 2011.

BRASIL. Constituição da República Federativa do Brasil: texto constitucional promulgado em 5 de outubro de 1988, com as alterações adotadas pelas emendas Constitucionais n os 1/1992 a 68/2011, pelo Decreto legislativo ${ }^{\circ}$ 186/2008 e pelas emendas Constitucionais de Revisão n os 1 a 6/1994.35 Ed. Brasília: Câmara dos Deputados, Edições Câmara, 2012.

. Ministério dos Transportes. CD-ROM. Banco de Informações dos Transportes. Brasília, 2011

Portaria $n^{\circ}$ 125, de 21 de março de 2014. Estabelece o conceito de cidades-gêmeas nacionais, os critérios adotados para essa definição e lista todas as cidades brasileiras por estado que se enquadram nesta condição. Seção 1. Diário Oficial da União, 24 mar. 2014.

BRICEÑO R. J. Del regionalismo estratégico al regionalismo social y productivo. Las transformaciones del modelo de integración del Mercosur. In: BRICEÑO RUIZ, José (Org.). El Mercosur y las complejidades de la integración regional. Buenos Aires: Teseo, p. 121-162, 2011.

A contribuição do Mercosul no debate sobre o modelo de integração no novo contexto do regionalismo latino-americano. In: MALLMANN, M. I.; RESENDE, E. S. A. (Org.). Mercosul 21 anos: maioridade ou imaturidade? Curitiba: Appris, p. 253-298, 2013. 
CARGNin, A. P. Políticas de desenvolvimento regional no Rio Grande do Sul: vestígios, marcas e repercussões territoriais. Brasília: Ministério da Integração Nacional, 2014.

CURZEL, R. As vicissitudes dos luxos comerciais nas diferentes fases do Mercosul. In: MALLMANN, M. I.; RESENDE, E. S. A. (Org.). Mercosul 21 anos: maioridade ou imaturidade? Curitiba: Appris, p. 61-93, 2013.

FURTADO, R. S. As fronteiras no âmbito do Mercosul: apontamentos sobre a formação da agenda política de integração fronteiriça. In: Univ. Rel. Int., Brasilia, v. 9, n. 1, p. 371-381, jan./jun. 2011. Disponível em: <http://www. publicacoesacademicas.uniceub.br/ index.php/relacoesinternacionais/article/ viewFile/1368/1344>. Acesso em: jun. 2016.

HOFFMAN, A.; COUTINHO, M.; KFURI, R. Indicadores e análise multidimensional da integração no Cone Sul. Revista Brasileira de Política Internacional, v. 51, n. 2, p. 98-116, jul./dez. 2008.

MALLMANN, M. I.; MARQUES, T. C. S. Leituras do MERCOSUL: diferentes percepções acerca do Bloco. Século XXI, Porto Alegre, v. 4, n. 2, jul./dez. 2013.

MEDEIROS, M. A.; MEUNIER, I.; COCKLES, M. Processos de Difusão Política e Legitimidade no Mercosul: Mimetismo Institucional e Mecanismos de Internalização de Normas Comunitárias. In: Contexto Internacional, Rio de Janeiro, v. 37, n. 2, maio/ago. 2015, p. 537-570. Disponível em: <http://www.scielo. br/pdf/cint/v37n2/0102-8529-cint-37-02-00537.pdf>. Acesso em: jun. 2016.

MIRANDA, J. C. Desafios à Integração da América do Sul. In: CALIXTRE, A. B.; BIANCARELLI, A. M.; CINTRA, M. A. M. (Ed.). Presente e futuro do desenvolvimento brasileiro. Brasília: IPEA, 2014.

MODOLO, V. O Mercosul Importa. A Política Regional de Mobilidade Territorial. In: Contexto Internacional, Rio de Janeiro, vol. 37, n 2, maio/ago. 2015, p. 571-595. Disponível em: <http://www.scielo.br/pdf/cint/v37n2/01028529-cint-37-02-00571.pdf>. Acesso em: jun. 2016.

MOREIRA, V. R.; MIRANDA, G. V. M. O papel do Brasil no MERCOSUL. In: Âmbito Jurídico, Rio Grande, XV, n. 96, jan. 2012. Disponível em: <http:// www.ambito-juridico.com.br/site/?n_link=revista_artigos_leitura\&artigo_ $\mathrm{id}=11029$ \&revista_caderno=19>. Acesso em: jun. 2016.

RIO GRANDE DO SUL. Plano de Desenvolvimento e Integração da Faixa de Fronteira do Estado do Rio Grande do Sul - PDIF/RS. Porto Alegre: 2012. 
SARAIVA, M. G.; BRICEÑO R. J. Argentina, Brasil e Venezuela: as diferentes percepções sobre a construção do Mercosul. Revista Brasileira de Política Internacional, Brasília, v. 52, n. 1, p. 149-166, jan./jun. 2009.

VENTURA, D. La gouvernance démocratique et l'intégration économique: regards croisés entre le Mercosur et l'Union Européenne. Droit et Société, n. 59, p. 93-103, 2005. Disponível em: <https://www.cairn.info/load_pdf. php?ID_ARTICLE=DRS_059_0093>. Acesso em: jun. 2016. 